\title{
Embalagem a vácuo: efeito no escurecimento e endurecimento do feijão durante 0 armazenamento
}

\author{
Vacuum package: its effect on the hardening and darkening of the \\ beans during storage
}

\author{
Rafaella Araújo Zambaldi Lima ${ }^{I^{*}}$ Laís Moretti Tomé \\ Celeste Maria Patto de Abreu ${ }^{\mathrm{I}}$
}

\section{RESUMO}

A influência do uso de embalagem a vácuo no controle do escurecimento e endurecimento do tegumento foi avaliada em feijões da cv. 'Pérola'. Os feijões após secos foram submetidos a diferentes embalagens: polietileno seladas a vácuo (espessura de $80 \mu \mathrm{m})$, polietileno seladas sem vácuo (espessura de $80 \mu \mathrm{m}$ ) e embalagem comercial (espessura de $20 \mu \mathrm{m}$ ), armazenados por oito meses em condições ambiente. Foram realizadas análises de umidade, tempo de cozimento, cor, atividade enzimática e compostos fenólicos, logo após a secagem e em intervalos de dois meses até o oitavo mês. O tempo de cozimento foi maior para os grãos acondicionados em embalagem comercial do que nas outras embalagens, ao final do armazenamento. Os grãos embalados em sacos de polietileno selados a vácuo apresentaram menor queda nos valores de $L^{*}$. As amostras da embalagem selada a vácuo apresentaram atividade da Peroxidase e Polifenoloxidase inferior aos grãos da embalagem comercial. $O$ teor de fenólicos totais não apresentou diferença significativa. $O$ uso da embalagem selada a vácuo foi eficiente em retardar o aumento no tempo de cozimento, o escurecimento do tegumento, a atividade das enzimas Polifenoloxidase e Peroxidase da cultivar 'Pérola', durante o armazenamento por oito meses em condição ambiente.

Palavras-chave: Phaseolus vulgaris, cozimento, cor, peroxidase, polifenoloxidase.

\section{ABSTRACT}

The influence of using vacuum packaging to control browning and hardening of the seed coat was evaluated in beans cv. 'Pérola'. The beans after dried, were subjected to different packaging: vacuum sealed polyethylene (thickness: $80 \mu \mathrm{m})$, no vacuum sealed polyethylene (thickness: $80 \mu \mathrm{m}$ ) and commercial

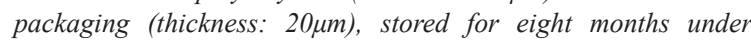
ambient conditions. Analyses of moisture, cooking time, color, enzymatic activity and phenolic compounds, shortly after drying and at intervals of two months until the eighth month. Cooking time was longer for the beans packed in commercial packaging, than in the other containers at the end of storage. The grains packed in polyethylene bags sealed under vacuum showed less decline in the values of $L *$. The samples will vacuum sealed package showed peroxidase activity and polyphenoloxidase below the grain of commercial packaging. The total phenolic content was not significantly different. The use of vacuum sealed package will was effective in slowing the increase in cooking time, the darkening of the integument, the activity of the enzymes polyphenoloxidase and peroxidase of bean $\mathrm{cv}$. 'Perola' during storage for eight months at ambient condition.

Key words: Phaseolus vulgaris, cooking, color, peroxidase, polyphenoloxidase.

\section{INTRODUÇÃO}

O feijão (Phaseolus vulgaris L.) fornece nutrientes essenciais, como proteínas, ferro, cálcio, vitaminas, carboidratos e fibras, é cultivado em quase todos os países e assume enorme importância devido ao seu baixo custo e, por ser um alimento de boa qualidade nutricional (OLIVEIRA et al., 2011). Apresenta uma ampla diversidade nos tipos de grãos, especialmente no que se refere à forma, ao tamanho $e$ às cores. No mercado brasileiro, esta diversidade é bem evidente. Contudo, a preferência é predominante sobre o grão tipo Carioca (SILVA et al., 2012). Em feijões que possuem tegumento de coloração clara, como os do tipo Carioca, ocorrem o escurecimento e endurecimento dos grãos durante o armazenamento. Este fenômeno causa perda considerável no valor comercial do feijão.

'Laboratório de Bioquímica, Departamento de Química, Universidade Federal de Lavras (UFLA), 37200-000, Lavras, MG, Brasil.

E-mail: rafazambaldi@hotmail.com.*Autor para correspondência. 
Assim que o feijão é colhido, inicia-se o processo de escurecimento enzimático do tegumento com consequente endurecimento do grão. Isto ocorre devido à oxidação de compostos fenólicos pelas enzimas Peroxidase (PER) e Polifenoloxidase (PFO), resultando na formação de pigmentos escuros e causando o endurecimento do grão (WHITEHEAD \& SWARDT, 1982). Esse processo é gradativo, acumulativo e irreversível. O armazenamento em condições ambiente aumenta o escurecimento do tegumento sendo influenciado pela alta umidade, alta temperatura e período de armazenamento. Feijões armazenados em atmosfera com altos níveis de dióxido de carbono e oxigênio têm o escurecimento do tegumento acelerado (BRACKMANN et al., 2002), causando seu endurecimento. Grãos escuros e endurecidos necessitam de maior tempo para cozimento e apresentam mudanças negativas na textura, sabor e valor nutricional.

A utilização de embalagens visa à preservação da qualidade do produto, estas criam uma barreira física entre produto e ambiente, diminuindo a troca de gases e vapores entre os dois ambientes. Este fato possibilita a redução da atividade de enzimas que necessitam de oxigênio para realizar a oxidação do substrato e, consequentemente, pode diminuir o escurecimento e endurecimento do tegumento dos grãos.

A utilização da embalagem a vácuo pode ser considerada uma alternativa eficiente para o armazenamento de feijões, por reduzir a níveis muito baixos a disponibilidade de oxigênio no interior da embalagem e a troca gasosa entre o produto e o ambiente. A espessura do filme utilizada nas embalagens é uma das principais variáveis relacionadas com a taxa de permeabilidade de vapor d'água. A alteração no teor de vapor d'água pode alterar o valor da umidade do produto embalado e acelerar a perda da qualidade. Quanto mais espesso é o filme utilizado, menor é a taxa de permeabilidade ao vapor d'água (SARANTÓPOULOS et al., 2002).

$\mathrm{O}$ presente trabalho objetivou avaliar a influência do uso de embalagem a vácuo no escurecimento e endurecimento de grãos de feijão tipo carioca, cv. 'Pérola', e a atividade das enzimas
PER e PFO durante o armazenamento por um período de oito meses, em condição ambiente.

\section{MATERIAL E MÉTODOS}

Feijões da cv. 'Pérola', provenientes de Ijaci, MG (latitude: $-21^{\circ} 10^{\prime} 12^{\prime \prime}$ e longitude: $-44^{\circ}$ 55'31"), foram colhidos (abril de 2010) e secos em terreiro cimentado, até atingirem a umidade de $12 \%$, em média. $\mathrm{O}$ delineamento experimental utilizado foi o inteiramente casualizado (DIC) em esquema fatorial (3x5) composto por três embalagens e cinco períodos de armazenamento $(0,2,4,6$ e 8 meses), com quatro repetições. O teste de Tukey a $5 \%$ de probabilidade foi utilizado para comparar os tratamentos dentro de cada tempo. Os modelos de regressão polinomiais, utilizados para tempo de armazenamento, foram selecionados com base na significância do teste $\mathrm{F}$ de cada modelo testado e pelo coeficiente de determinação.

Os grãos foram acondicionados em embalagens contendo $1 \mathrm{~kg}$ de feijão, de acordo com a tabela 1 . A espessura de $20 \mu \mathrm{m}$ foi escolhida para utilização neste experimento por ser o padrão utilizado pela maioria dos vendedores de feijão no varejo. Enquanto a embalagem de espessura de $80 \mu \mathrm{m}$ foi utilizada por permitir a manutenção do vácuo no seu interior, devido à menor taxa de permeabilidade de gases.

As amostras foram armazenadas em condições ambiente $\left(20^{\circ} \mathrm{C} \pm 5,26^{\circ} \mathrm{C}\right.$ e $55,2 \% \pm 16,8 \%$ UR) e as análises foram realizadas no primeiro dia de armazenamento (tempo 0) e em intervalos de dois meses. Para a determinação da umidade do grão, durante o armazenamento, utilizou-se estufa a $105^{\circ} \mathrm{C}$ até os grãos obterem peso constante (AOAC, 1992). A avaliação do cozimento foi realizada com o cozedor de Mattson (25 pinos), as amostras foram embebidas em água destilada, por 13h (RODRIGUES et al., 2005), à temperatura ambiente $\left( \pm 20^{\circ} \mathrm{C}\right)$. O tempo necessário para que 13 pinos (metade +1 ) caíssem foi utilizado para calcular o tempo médio de cozimento de cada amostra (PROCTOR \& WATTS, 1987). A análise da cor do tegumento foi realizada com colorímetro Minolta CR310. Os dados foram coletados pelo valor do eixo $L^{*}$

Tabela 1 - Composição dos tratamentos

\begin{tabular}{llcl}
\hline Embalagem & Material & Espessura & Selagem \\
\hline 1 & Sacos de polietileno transparente & $80 \mu \mathrm{m}$ & a vácuo \\
2 & Sacos de polietileno transparente & $80 \mu \mathrm{m}$ & sem vácuo \\
3 & Sacos de polietileno transparente & $20 \mu \mathrm{m}$ & sem vácuo \\
\hline
\end{tabular}

Ciência Rural, v.44, n.9, set, 2014. 
que indica a luminosidade do grão, identificando um possível escurecimento (McGUIRE, 1992).

No ensaio enzimático da PER e PFO, as amostras foram trituradas em moinho refrigerado (30 segundos), formando uma farinha. A extração enzimática foi a mesma para ambas as enzimas, $2 \mathrm{~g}$ da farinha homogeneizada em liquidificador (30 segundos) com tampão fosfato $0,1 \mathrm{~mol} \mathrm{~L}^{-1}(\mathrm{pH} 7,0)$, contendo polivinilpirrolidona (PVP) insolúvel, após filtrado e centrifugado $\left(15.000 \mathrm{~g}\right.$ por 15 minutos a $4^{\circ} \mathrm{C}$ ), o sobrenadante foi utilizado para o ensaio enzimático (ZAUBERMAN et al., 1991). A atividade da PER foi determinada segundo KHAN \& ROBINSON (1994). Os meios de reação foram o guaiacol $1 \%\left(\mathrm{v} \mathrm{v} \mathrm{v}^{-1}\right), \mathrm{H}_{2} \mathrm{O}_{2}$ $0,3 \%\left(\mathrm{v} \mathrm{v}^{-1}\right)$, extrato enzimático e tampão fosfato de sódio $(\mathrm{pH} 7,0)$. A reação foi acompanhada durante 2 minutos (leituras em intervalo de 2 segundos, a $30^{\circ} \mathrm{C}$ ), em espectrofotômetro (Espectro Vision). A atividade foi expressa em unidade (atividade capaz de alterar 0,001 de absorbância a 470nm) por minuto por grama de farinha $\left(\mathrm{U} \mathrm{g}^{-1}\right)$ e calculada utilizando-se dados relativos à porção linear do gráfico absorbância x tempo. Na determinação da atividade da PFO, foi utilizado catecol e extrato enzimático como meio de reação, durante 5 minutos (ZAUBERMAN et al., 1991), com leituras efetuadas em intervalo de 2 segundos, a $30^{\circ} \mathrm{C}$, em espectrofotômetro. $A$ atividade foi expressa na mesma unidade da PER.

A extração dos compostos fenólicos totais foi realizada segundo método descrito por SWAIN \& HILLIS (1959) e a dosagem da amostra, de acordo com método de Follin-Denis (AOAC, 1992). Os resultados foram expressos em $\mathrm{mg}$ de ácido tânico. $100 \mathrm{~g}^{-1}$ de amostra.

\section{RESULTADOS E DISCUSSÃO}

Não houve variação significativa na umidade dos grãos durante o período de armazenamento em nenhum tipo de embalagem $(12,2 \% \pm 1,0 \%)$. Esses dados reforçam a hipótese de que as embalagens são eficientes para formarem uma barreira entre o interior da embalagem e o meio ambiente exterior, minimizando trocas gasosas. Apesar de ter ocorrido variação nos valores de temperatura e umidade relativa do ar durante o armazenamento, os filmes de polietileno, das diferentes espessuras, ofereceram boa barreira ao vapor d'água, impedindo que ocorresse alteração na umidade dos grãos. Os polietilenos são, por natureza, apolares, e excelente barreira para a umidade e vapor d'água (MORALES et al., 2010), o que pode variar com a espessura do filme. Segundo ALVES et al. (2011), os filmes de polietileno de $20 \mu \mathrm{m}$ e $80 \mu \mathrm{m}$ de espessura apresentam taxa de permeabilidade ao vapor d'água de 7,04 e 4,94g água $\mathrm{m}^{-2} \operatorname{dia}^{-1}$ (a $38^{\circ} \mathrm{C}$ com $90 \% \mathrm{UR}$ ), respectivamente. Um material que apresente uma taxa de permeabilidade ao vapor d'água menor que $8,0 \mathrm{~g}$ água $\mathrm{m}^{-2} \mathrm{dia}^{-1}$ (a $38^{\circ} \mathrm{C} \mathrm{com}$ 90\%UR) é considerado de alta barreira (GARCIA et al.,1989).

O tempo de cozimento foi influenciado pelo tipo de embalagem e tempo de armazenamento, houve aumento para todos os tratamentos, a partir do sexto mês de armazenamento, até o final do período. Os grão mantidos em embalagem selada a vácuo apresentaram menor tempo de cozimento em relação aos demais tratamentos (Figura 1), o

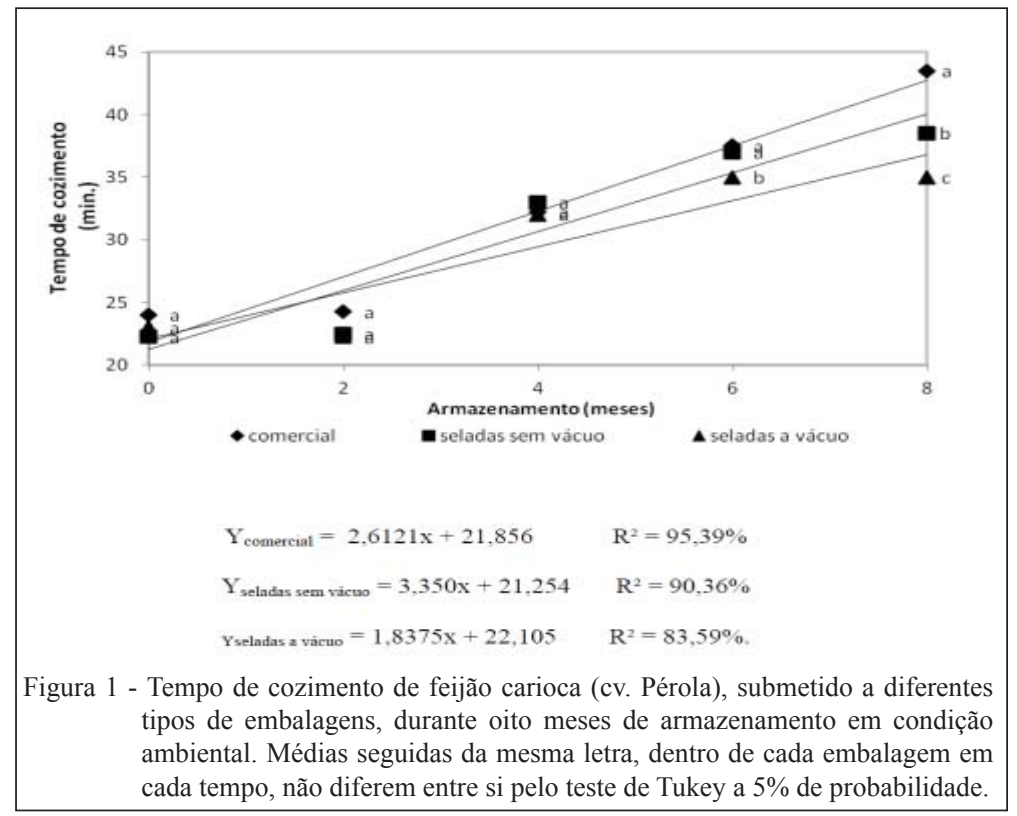

Ciência Rural, v.44, n.9, set, 2014. 
que pode ser explicado pela menor disponibilidade de oxigênio, no interior da embalagem selada a vácuo, impedindo a ação das enzimas e a formação de fenóis de alto peso molecular, responsáveis pelo endurecimento e escurecimento dos grãos. No trabalho realizado por OLIVEIRA et al. (2011), com feijões da mesma cultivar, armazenados por 6 meses sem embalagem e refrigerado, o tempo de cozimento foi de 30,4min. A diferença deste tempo com o dos grãos armazenados em embalagem selada a vácuo (35min), do presente trabalho, se deve as diferentes condições de armazenamento. A refrigeração diminui a atividade enzimática e, portanto, o escurecimento e endurecimento dos grãos. A utilização da embalagem a vácuo pode ser uma alternativa, com vantagem econômica em relação ao sistema refrigerado.

Houve interação significativa entre as embalagens e os tempos analisados para luminosidade (eixo $\mathrm{L}^{*}$ ), ocorreu um decréscimo ao longo do período avaliado (Figura 2). Assim como no tempo de cozimento, a partir do sexto mês de armazenamento, os grãos embalados e selados a vácuo apresentaram menor queda na luminosidade, apresentando ao final do armazenamento uma queda de $6,9 \%$, enquanto os grãos embalados sem vácuo e os mantidos em embalagem comercial apresentaram queda de 10,2\% e $15,2 \%$, respectivamente, para o mesmo período. A luminosidade é um parâmetro importante da cor, pois, quanto menor seu valor, mais escuro e consequentemente mais endurecido o grão. Resultados semelhantes foram relatados por OLIVEIRA et al. (2011) estudando a mesma cultivar. Eles verificaram queda na luminosidade (12\%) após armazenamento refrigerado por seis meses, sem embalagem, valor superior ao do presente trabalho, afirmando que a embalagem selada a vácuo retarda o escurecimento e endurecimento do grão. Segundo BRACKMANN et al. (2002), o armazenamento em minisilos (5L), por um período de 9 meses, em ar ambiente, resultou em maior escurecimento dos feijões (cv. 'Pérola') do que o armazenamento em atmosfera controlada (fluxo contínuo de $\mathrm{N}_{2}$ de $1,1 \mathrm{~L} \mathrm{~h}^{-1}$ ). O valor da luminosidade foi de 51,7, (amostras mantidas em atmosfera controlada), ao final do período de armazenamento, valor próximo ao encontrado neste trabalho nos grãos embalados e selados a vácuo $(50,19)$ durante oito meses de armazenamento. Provavelmente, a presença de oxigênio acelera as oxidações enzimáticas e, assim, o escurecimento do tegumento de feijões.

Houve interação significativa entre a embalagem e o tempo de armazenamento para a atividade da PER. No primeiro dia de armazenamento, pode-se observar alta atividade da PER (Figura 3), indicando que o escurecimento e endurecimento dos grãos são processos iniciados desde a colheita e que aumentam durante o armazenamento. A atividade da PER nos grãos mantidos em embalagem comercial foi superior ao dos outros tratamentos desde o segundo mês até o final do armazenamento $\left(843,6 \mathrm{U} \mathrm{g}\right.$ de farinha ${ }^{-1}$ $\left.\min ^{-1}\right)$. Os grãos embalados a vácuo apresentaram

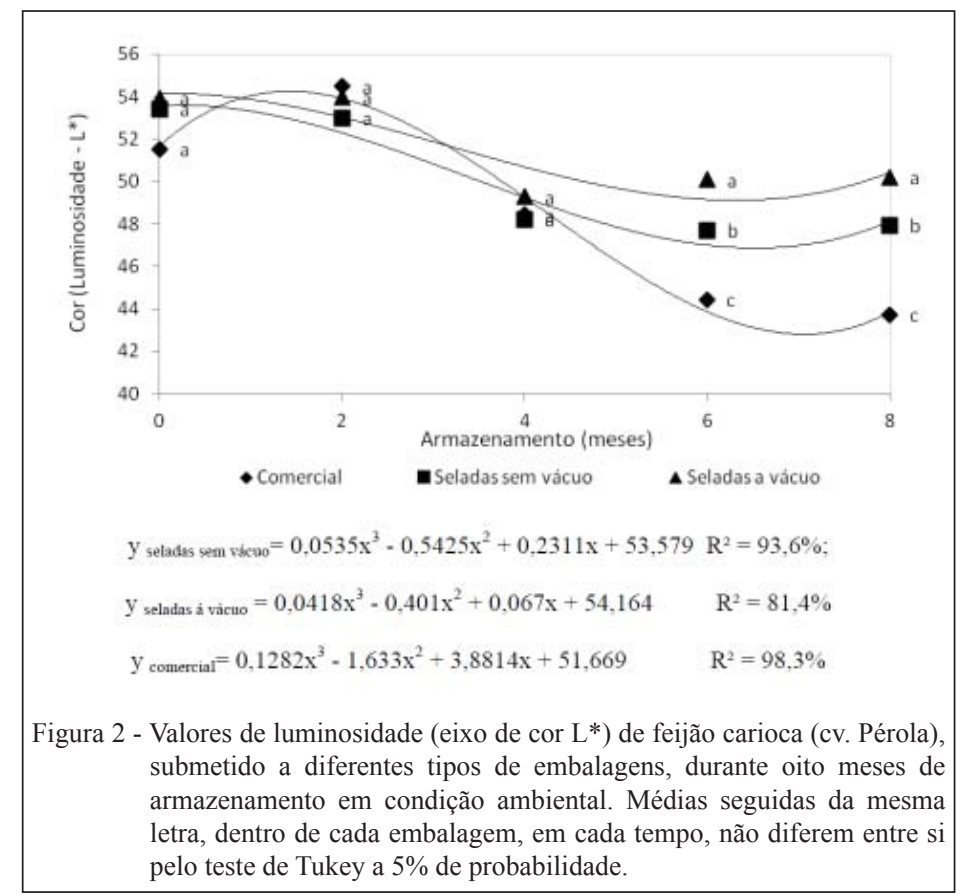

Ciência Rural, v.44, n.9, set, 2014. 


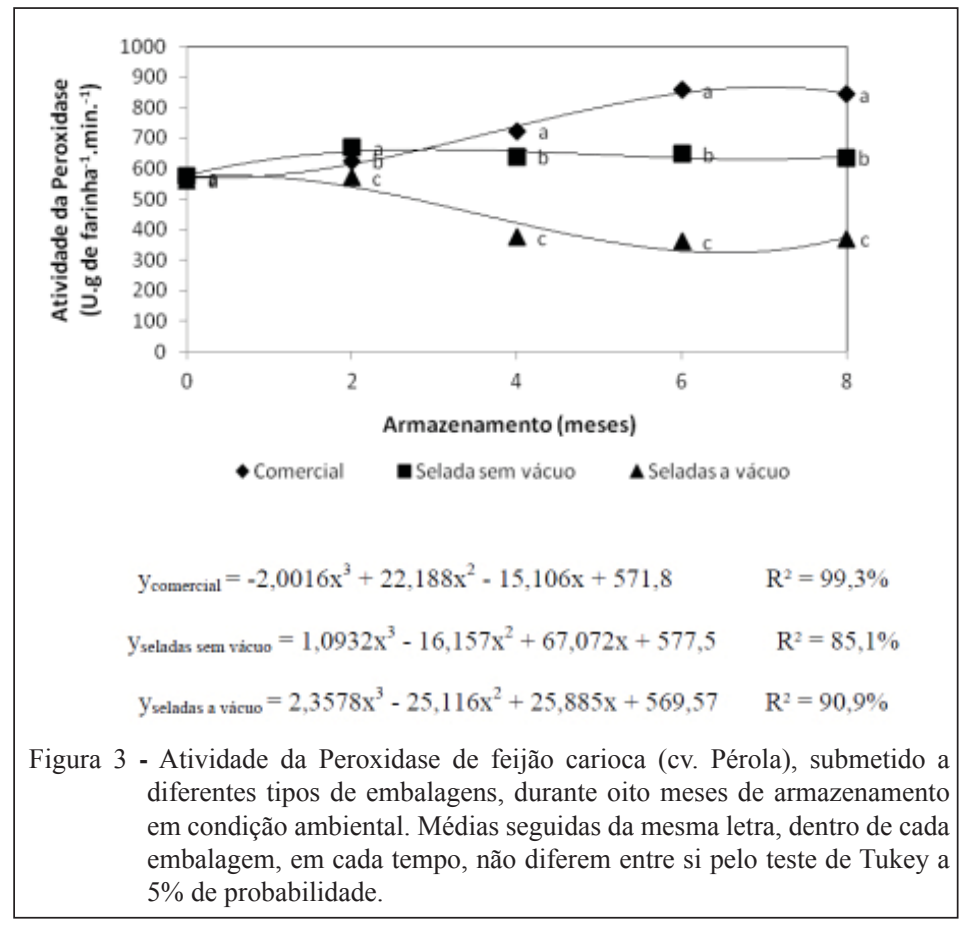

menor atividade ao final do período de armazenamento (368,6U g de farinha $\left.{ }^{-1} \mathrm{~min}^{-1}\right)$. A queda na atividade da PER nos grãos mantidos em embalagem á vácuo pode ser explicada pela baixa disponibilidade de oxigênio, impedindo desta forma a oxidação dos fenólicos. MOURA et al. (1999) identificaram um aumento na atividade da PER durante o armazenamento de feijões cariocas. A PFO já apresentava atividade antes do início do armazenamento (Figura 4). Nos grãos embalados a vácuo, a atividade da $\mathrm{PFO}$ diminuiu até o quarto mês de armazenamento, devido à baixa disponibilidade de oxigênio, o mesmo caso não ocorreu com os outros tratamentos. A embalagem comercial apresentou maior aumento da atividade a partir do quarto mês, até o final do armazenamento, em relação aos outros tratamentos. Este fato ocorreu devido à menor espessura desta embalagem, o que pode ter facilitado maior difusão de oxigênio do ambiente para dentro da embalagem. O feijão carioca apresentou elevada atividade da PER e PFO logo após a colheita (Figuras 3 e 4). Esse fato somado aos altos teores de compostos fenólicos justifica o escurecimento e endurecimento do grão ao longo do armazenamento, causando perda de qualidade. ESTEVES et al. (2002) encontraram valores semelhantes para a atividade de ambas as enzimas no feijão carioca após a colheita (PFO 8800U g farinha ${ }^{-1}$ min $^{-1}$ e PER 520U g farinha ${ }^{-1}$ $\mathrm{min}^{-1}$ ). RIOS et al. (2002) relataram o escurecimento do tegumento dos grãos de feijão após seis meses de armazenamento e que a cor mais escura do tegumento pode ser consequência do aumento da atividade da enzima PFO associada à atividade da enzima PER.

O teor de compostos fenólicos totais não apresentou diferença significativa para as diferentes embalagens utilizadas durante o armazenamento

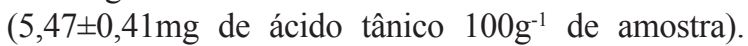
Este fato pode ser esclarecido pela técnica de extração utilizada para a detecção de fenólicos totais sem distinção entre monoméricos e poliméricos, o que pode justificar os valores permanecerem constantes durante o armazenamento. Estes dados são diferentes dos encontrados por RIOS et al. (2002), que identificaram um aumento no teor de compostos fenólicos totais durante o armazenamento de feijão carioca por oito meses em condições ambientais. MOURA et al. (1999) observaram uma variação nos teores de fenólicos totais durante o armazenamento de feijão carioca por 8 meses em condições ambiente. Há, no entanto, uma divergência quanto ao fato de fenóis totais aumentarem ou diminuirem com o armazenamento dos grãos. Alguns estudos demonstraram que um aumento nos fenóis está associado com o envelhecimento dos grãos, outros estudos têm mostrado que o teor de fenóis totais tende a diminuir com o armazenamento (HINCKS \& STANLEY, 1986). As diferenças de procedimentos de extração foram provavelmente a causa dessa divergência. Novos estudos deverão ser realizados para a extração dos compostoss fenólicos nos diferentes pesos moleculares. 


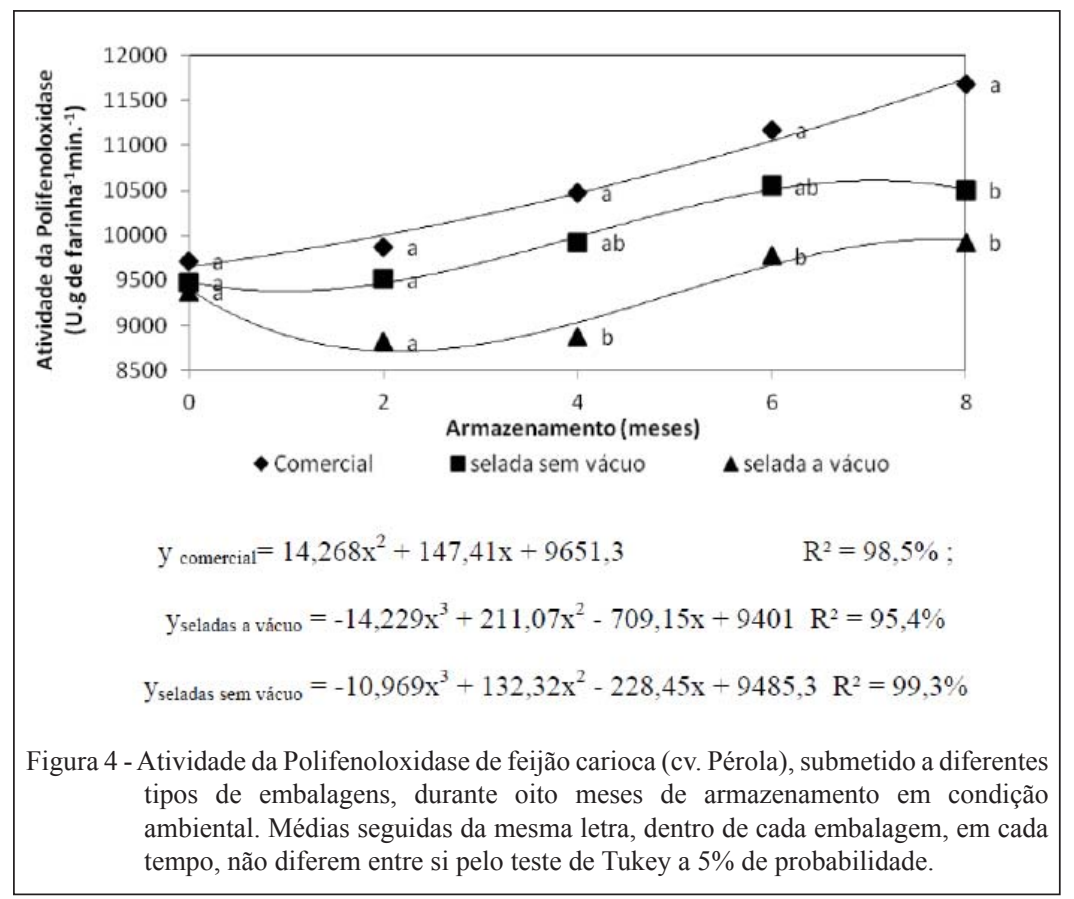

\section{CONCLUSÃO}

A utilização das embalagens de polietileno ( $80 \mu \mathrm{m}$ de espessura) seladas ou não a vácuo permitiu o menor escurecimento e endurecimento dos feijões da cultivar 'Pérola', grupo comercial Carioca. No entanto, a embalagem selada a vácuo foi mais eficiente em diminuir a atividade das enzimas PER e PFO, retardando ainda mais o escurecimento e endurecimento dos feijões durante o armazenamento por oito meses em condição ambiente.

\section{AGRADECIMENTOS}

Ao Conselho Nacional de Desenvolvimento Científico e Tecnológico (CNPq) e a Coordenação de Aperfeiçoamento de Pessoal de Nível Superior (CAPES) pelo apoio financeiro.

\section{REFERÊNCIAS}

ALVES, R.M.V. et al. Seleção de materiais em embalagens para derivados de batata doce de polpa alaranjada. Teresina: IV Reunião de Biofortificação, 2011. 5p.

ASSOCIATION OF OFFICIAL ANALYTICAL CHEMISTRY. Official methods of analysis of the Association on Analytical Chemistry. 12.ed. Washington, 1992. 1115p.

BRACKMANN, A. et al. Conservação de três genótipos de feijão (Phaseolus vulgaris L.) do grupo carioca em armazenamento refrigerado e em atmosfera controlada. Ciência Rural, v.32, p.911-915, 2002. Disponível em: <http://www.scielo.br/scielo. php?script $=$ sci_arttext\&pid $=$ S0 $10384782002000600001 \& \operatorname{lng}=$ en\&nrm=iso $>$. Acesso em: 26 fev. 2012. doi: 10.1590/S010384782002000600001

ESTEVES, A.M. et al. Comparação química e enzimática de seis linhagens de feijão (Phaseolus vulgaris L.). Ciência e Agrotecnologia, v.26, n.5, p.999-1005, 2002.

GARCIA, E.E.C. et al. Embalagens plásticas: propriedades de barreira. Campinas: ITAL, 1989. 44p.

HINCKS, M.J.; STANLEY, D.W. Multiple mechanism of bean hardening. Journal of Food Technology, v.21, p.731-50, 1986.

KHAN, A.A.; ROBINSON, D.S. Hydrogen donor specificity of mango isoperoxidases. Food Chemistry, v.49, n.4, p.407-410, 1994.

McGUIRE, R.G. Reporting of objective colour measurements. Hort Science, v.27, p.1254-1255, 1992.

MORALES, A.R. et al. Nanocompósitos de PEAD/PEBDL Avaliação da esfoliaqção da argila organolífica pela aplicação do modelo de Nielsen e das propriedades mecânicas, óticas e permeabilidade. Polímeros: Ciência e Tecnologia, v.20, n.1, p.39-45, 2010.

MOURA, A.C. de C. Análises físico-químicas e enzimáticas antes e após armazenamento em grãos de feijão (Phaseolus vulgaris, L.) submetidos a diferentes tempos e tipos de secagem. 1999. 70f. Dissertação (Mestrado em Ciência dos Alimentos) Curso de Pós-graduação em Ciência dos Alimentos, Universidade Federal de Lavras, MG.

OLIVEIRA, V.R. et al. Qualidade para o cozimento e composição nutricional de genótipos de feijão com e sem armazenamento sob refrigeração. Ciência Rural, v.41, n.5, p.746-752, 2011. Disponível em: $<$ http://www.scielo.br/scielo.php?script=sci_artte 
$\mathrm{xt} \& \mathrm{pid}=\mathrm{S} 010384782011000500002 \& \operatorname{lng}=\mathrm{en} \& \mathrm{nrm}=\mathrm{iso}>$. Acesso em: 05 fev. 2012. doi: 10.1590/S0103-84782011005000050.

PROCTOR, J.R.; WATTS, B.M. Development of a modified Mattson bean cooker procedure basead on sensory panel cookability evaluation. Canadian Institute of Food Science and Technology Journal, v.20, n.1, p.9-14, 1987.

RIOS, A.O. et al. Efeitos da época de colheita e do tempo de armazenamento no escurecimento do tegumento do feijão (Phaseolus vulgaris, L.). Ciência e Agrotecnologia, v.26, p.550-558, 2002.

RODRIGUES, J.A. at al. Correlação entre absorção de água e tempo de cozimento de cultivares de feijão. Ciência Rural, v.35, n.1, p.209-214, 2005

SARANTÓPOULOS, C.I.G.L. et al. Embalagens plásticas flexíveis: principais polímeros e avaliação de porpriedades. Campinas CETEA, 2002. 267p.
SILVA, C.A. et al. Chemical composition as related to seed color of common bean. Crop Breeding and Applied Biotechnology, v.12, n.2, p.132-137, 2012

SWAIN, T.; HILLIS, W.E. The phenolic constituents of Prunus domestica I.: The quantitative analysis of phenolic constituent. Journal of Science of Food and Agriculture, v.10, n.1, p.63-68, 1959.

WHITEHEAD, C.S.; SWARDT, G.H. Extraction and activ of polyphenoloxidase and peroxidase from senescing leaves of Protea nerifolia. South African Journal of Botany, v.1, p.127130, 1982.

ZAUBERMAN, G. et al. Postharvest retention of the red colour of litchi fruit pericarp. Scientia Horticulturae, v.46, n.1-2, p.8997, 1991. Disponível em: <http://www.sciencedirect.com/science/ article/pii/0304423891900303>. Acesso em: 12 nov. 2011. doi:10.1016/0304-4238(91)90030-3 